\title{
Impacts of Academic Cultures on Concept Reconstruction of Universities
}

\author{
Mingchao Li \\ Zhuhai College of Jilin University \\ Zhuhai, China
}

\begin{abstract}
To accommodate needs of the society under the new normal state, universities have carried out many reforms from the perspective of policies. Due to impacts of complicated internal and external development environment as well as multiple social factors, concept construction is weak and even deficient in universities. As a consequence, new and old conflicts are interwoven. To dissolve conflicts that emerge during university development and construction for harmonious development of universities, modern universities shall restore to their original state to reshape university concepts. In addition, free, relaxed, united and fair academic cultures that attach utmost importance to academic work shall be developed in universities for effectively promoting reconstruction of university concepts.
\end{abstract}

Keywords-new normal; academic cultures; university concepts

\section{INTRODUCTION}

In May 2014, Xi Jinping said during his visit in Henan Province that China was still in a stage of development with important strategic opportunities, so we should increase our confidence, adapt to the new normal situation according to periodical characteristics of current economic growth in China and maintain strategically normal attitudes." [1] Although this means economy has developed under a new normal state of economic growth in China and matters about economic construction, it is also adaptable to the introduction of the concept of new normal economy into concept construction of universities after its transformation. Universities have been constructed in sync with development of China. In particular, number of universities and students have increased day after day since the reform and opening up of China. Tremendous changes have happened to school-running patterns and concepts of universities too. Universities have tended to be diversified, while some new problems with university construction and development remain to be urgently solved. In the process of social modernization and university secularization, universities have simultaneously attached importance to benefits of universities, officials and businessmen as well as management and systems with totally different functions. Administrative and corporate school-

Research program: This paper is a periodical research outcome of Provincial Innovation Program of the Department of Education of Guangdong Province for Moral Education of Universities in 2015 and Ideological and Political Education Program for Universities of Guangdong Province in 2015 (Grant No.: 2015DYYB029; Topic: Promoting the Construction of Longterm Mechanism for Moral Education of Private Universities by Ethical Cultivation of Teachers). running models have become common characteristics of Chinese universities. It is still universal that there are more buildings than teachers, more importance is attached to equipment than talents, and more attention is paid to images than connotations. In China, higher education system is still not creative enough, because universities have generally become training or processing stations of technical talents that meet social needs. What's worse, concepts about political achievements, formalism and imitation of malpractices are rather prevalent. Even if universities would have been noble and sacred, adverse practices like academic misconducts have never disappeared in spite of repeated prohibitions. Defects of planned system and official standards still firmly exist.

In the next five years and a longer period, global economy will recover through hardships after in-depth adjustments. In China, economy will develop under a new normal state and adapt to this state with three major characteristics, including changes to speed of economic growth, structural optimization and transformation of driving forces. For new normal economy, profound changes will happen to relationships between talent supply and demand. In face of profound changes to economic structures, industries will be upgraded at a faster pace, while social and cultural construction will be constantly promoted. In particular, with the implementation of major national strategies such as innovation-driven development, made in China 2025, internet + , mass entrepreneurship and innovation, "one belt and one road", there will be new higher requirements for transformations. In the critical periods of developing and transforming higher education during the "13th Five-year Plan", it will become urgent for redeveloping "university concepts". Undoubtedly, it will be valuable for development of universities in the future as long as education concepts of universities in a new era are explored by reflecting on and examining development of university concepts from the perspective of academic cultures.

\section{CONNOTATIONS OF ACADEMIC CULTURES IN UNIVERSITIES}

What are academic cultures? Burton R. Clark considers that due to differences in expression of academic work and means of task arrangements, people of different parts within the academic system inevitably develop distinct norms and values, namely academic beliefs or cultures. Inherently, universities are matrix organizations made up of "disciplines" and "colleges". Hence, they are not only a kind of social 
structures, but also cultures. Inside universities, beliefs are essential for academic cultures. Thus, academic cultures may be understood based on academic beliefs of disciplines and organizational atmosphere of colleges. Disciplinary cultures are origins for scholars to be loyal to academic work, while college cultures are social psychological environment inside universities. Incorporating and penetrating into each other, they jointly compose the soft environment indispensable for academic development and talent cultivation in universities.

What are disciplinary cultures? Disciplinary cultures are the sum of the languages, value standards, ethical norms, thinking and behavioral methods accumulated during formation and development of disciplines. In the course of developing disciplines, members of disciplinary organizations constantly exchange, communicate and cooperate with each other. Through various interactions, they psychologically develop certain senses of identity and belonging. Progressively, some common values, concepts and behavioral norms may come into being, finally developing into disciplinary cultures of certain cultural characteristics. As the most fundamental academic cultures, disciplinary cultures are closely connected with features of disciplines. "Models are what members of a scientific groups share; in turn, a scientific group is composed of people who share a model." In spite of their differences, disciplinary cultures also have common characteristics, and scholars of all disciplines have fundamental common qualities, such as seeking freedom, seeking truths and daring to innovate, which are valuable for integrating disciplinary cultures and promoting prosperity of disciplines.

What are college cultures? As places for convergence of various disciplines, universities are organizational carriers or institutions of disciplines. Whatever the specific disciplines are, universities may have their own local academic atmosphere or organizational climate and cultures, impacting their scholars and different academic organizations by their cultures, which are just known as "college cultures". For instance, Tsinghua University's spirit of "making unremitting efforts for selfimprovement and social commitment" and Peking University's spirit of "thinking freely and being all-inclusive" are portrayals of college cultures. Establishing basic beliefs for university education and management activities, "college cultures" upgrade common characteristics of disciplinary cultures. As driving forces of universities' survival and development, these cultures have distinctive characteristics and influence development of universities. All in all, academic cultures are attributes and elements of groups and organizations producing knowledge, so it is important for exploring rules of higher education from the perspective of academic cultures.

In fact, universities are essentially matrix organizations made up of disciplines and colleges under open disciplinary and relatively closed college environment. Therefore, academic cultures of universities may be understood based on academic beliefs of disciplines and organizational atmosphere of colleges, which may jointly compose internal environment for academic development of universities by incorporating and penetrating into each other.

\section{SIGNIFICANCE FOR RESHAPING UNIVERSITY CONCEPTS} IN A NEW ERA

As relatively stable group mind-set and mental state of a university, university concept is the most typical spiritual trait that is accumulated through long-term educational practices. It indicates overall outlook, achievements, characteristics, cohesion, charisma and vitality of a university. University concept means a university freely presents its traits and landscapes accumulated by and reflected from the process of realizing inherent transcendence based on its intrinsic nature. As essential stipulation of a university, it is a permanent driving force and source of the university. It plays a significant role in highlighting image, characteristics, styles and level of a university.

In general, university concepts are spirits, mainly characterized by scientific, innovative, free and democratic spirits. Scientific spirits of universities don't only cover a range of behavioral norms for scientific research, but also include pursuit of value in conducting scientific research. Close integration with humanistic spirits is considered as the highest value guideline of scientific research. Innovative spirits of universities mainly refer to "enterprising" spirits orienting towards scientific research, social development and talent cultivation, reflected in choosing, criticizing and innovating cultures. Free spirits of universities are mainly indicated from freedom of thoughts, academic freedom and freedom of speech Democratic spirits of universities primarily mean the spirits of seeking institutional democracy and social democratic progress, cohering historic cultures with spirits of times.

As souls of universities, university concepts play critical roles in development of universities. As pointed out by a scholar of higher education named Abraharn Flexner, "on the whole, they are more effective for guaranteeing high standards of universities than any other facilities or organizations." However, with profound changes to economic systems, social structures, interest patterns and thoughts, China has encountered challenges and difficulties in its higher education owing to impacts of market economy and utilitarianism under a new normal state. In new periods, concepts of Chinese universities tend to be vague.

It is thus clear that it has become relatively universal to manage universities by administrative models and solve academic problems by administrative thinking and decisions. It is just in such noisy wave of socialization that university concepts have been gradually overshadowed and even disappear in secret. As a consequence, universities appear to have forgotten their pursuits of concepts. University concepts are souls of universities' development and prosperity. It is necessary for sound development of Chinese higher education in a new era by clarifying concepts of modern universities, further reshaping and carrying forward these concepts. As mentioned by Abraham Flexner, "universities are not vanes. To respond to all popular and prevailing customs of a society, universities shall offer some things to the society. These things aren't what the society wants, but what it needs." Only in this way will the society constantly achieve sound development under the guidance of critical and retrospective spirits. Therefore, to seek and reshape university concepts isn't only 
necessary for stimulating and facilitating development of universities, but also a need for reshaping and upgrading such concepts. Hence, lack of university concepts must arouse adequate concern. "To reshape university concepts" is a necessary requirement for revitalizing Chinese civilization and a loud call of an era.

\section{IMPACTS OF ACADEMIC CULTURES ON UNIVERSITY CONCEPTS}

It is helpful for developing correct concepts about higher education by studying academic cultures. To be sure, it is an unshirkable responsibility of modern universities to integrate themselves into society, serve the society and facilitate development of the society. No matter how much knowledge they have, universities can hardly present their value if they are closed and conservative. Universities will definitely lose their skills for their survival if one-sided emphasis is laid by universities on serving the society and discarding their inherent qualities. Therefore, for universities, a balance shall be achieved among serving the society, knowledge dissemination and innovation in terms of their concepts, in order that universities can move forward by maintaining their distinct intrinsic characteristics while keeping certain distance from external environment. For both purposes, efforts shall be made to realize sound interactions between universities and the society. Basic research shall be conducted to guide social development and promote social progress by applied sciences. It is necessary to simultaneously sustain unique university concepts and provide intellectual products needed by the society. To attain this goal, the only way is to build open universities at the cost of not losing themselves. In this case, it is favorable for universities to integrate and complement with each other. Moreover, it is more helpful for them to promote the development of each other.

It is beneficial for strengthening cohesion of modern universities by examining academic cultures. As special social organizations and places of educational research, universities engage in knowledge production and attach great importance to spiritual power. What scholars focus on pursuing are enriching their spiritual life and realizing their ambitions instead of satisfactory material life. Hence, university concepts are important for talent accumulation. Nevertheless, universities are loose organizations of multiple disciplines, where there are two categories of loyal scholars, who are loyal to their specialties and professions respectively. Great differences exist in disciplines and specialties among universities, which have complicated relationships in cooperation, exchange and competition. In universities which are sophisticated intellectual communities, it is just academic cultures that maintain goals of universities and coordinate academic and social relationships between experts and scholars.

Various disciplines are cohered by academic cultures, so professional experts and scholars may embark on research and teaching according to certain norms. University concepts are developed via exchange, cooperation and competition. As President of the University of Chicago, Hugo Sonnenschein has pointed out in evaluating functions of group cooperative organizations that, "what they take pride in the University of
Chicago consists in that their scholars deeply realize their major responsibilities for exchanging views and commenting on each other. This is not a "respectable" process, as it may make those indolent, weak and rigid people upset. In the mean time, it may activate the thinking of some people, in order that they can become vital and energetic. By exchanging and evaluating each other's views, people may review if their own opinions are logical, learn how to frankly voice their opinions about sensitive questions and draw lessons from others' views. This practice may promote the "boiling" of a pot mixed with knowledge. This is more influential and vital than separately proposed views." [2]

It is helpful for facilitating the development of universities' capacities for academic production by exploring academic cultures. Academic cultures may create a type of intangible "cultural fields", where scholars may feel ideological impacts of such "fields", restricted and stimulated by them. Just as mentioned by Firestone and Wilson, "playing great roles in defining teachers' contributions to their tasks, cultures of educational organizations stimulate teachers' vitality for fulfilling tasks of their organizations, their loyalty and contribution to the organizations. As representatives of their emotional attachments to organizations and organizational ideals, they don't only impel teachers' wills for obeying the rules and regulations that restrict them in organizations, but also urge them to realize organizational ideas as personal value, so as to work full of energy by attaining expected objectives of the organizations" [3]. Scholars' power impacts each other inside "fields", where such impacts are tremendous and usually extended beyond colleges to communities and even the society, thereby imposed on external environment of universities to certain extent.

\section{CONCLUSION}

Reconstruction of university concepts under the normal state is profoundly impacted by academic cultures. By penetrating cultures, influencing college cultures and spreading outstanding academic styles and school spirits, academic cultures of universities exert profound and marvelous impacts upon university concepts.

\section{REFERENCES}

[1] Graphic Database of People's Daily. Xi Jinping's Emphasis in His Visit of Henan Province on: Both Deepening Reform and Taking Advantage of Creative Ideas to Ensure Healthy and Sustainable Development of Economy, Social Harmony and Stability [EB/OL]. (2014 - $05-11)$ [2016 - $01-05]$. http: / /paper. people. com. cn /rmrb /html /2014 - 05/11/nw. D110000renmrb_20140511_2-01. htm.

[2] Zhang Min, Yang Yuan. University of Chicago [M]. Changsha: Hunan Education Publishing House, February 1994.

[3] WILLIAM A FIRESTON E, BRUCE L W ILSON.Using Bureaucratic and Cultural Linkages to ImproveInstruction: The High School Princ ipal' sContribution [M ]. Eug ene: Univ er sity o f Oreg onPress, 1983. 14-15. 